\title{
Endothelium-Dependent Relaxation in Response to Poly-L-Arginine in Canine Coronary Arteries. Implications about Hyperpolarization as a Mechanism of Vasodilatation
}

\author{
Paulo R. B. Evora, Paul J. Pearson, Alfredo José Rodrigues, Fernanda Viaro, Hartzell V. Schaff
}

Rochester, Minnesota (USA) - Ribeirão Preto, SP (Brazil)

\begin{abstract}
Objective - To study the mechanism by which poly-Larginine mediates endothelium-dependent relaxation.

Methods - Vascular segments with and without endothelium were suspended in organ chambers filled with control solution maintained at $37^{\circ} \mathrm{C}$ and bubbled with 95\% $\mathrm{O}_{2} / 5 \% \mathrm{CO}_{2}$. Used drugs: indomethacin, acetycholine, EGTA, glybenclamide, ouabain, poly-L-arginine, methylene blue, $N^{G}$-nitro-L-arginine, and verapamil and $N^{G}$-monomethyl-L-arginine. Prostaglandin $F_{2 a}$ and potassium chloride were used to contract the vascular rings.
\end{abstract}

Results - Poly-L-arginine $\left(10^{-11}\right.$ to $\left.10^{-7} \mathrm{M}\right)$ induced concentration-dependent relaxation in coronary artery segments with endothelium. The relaxation to poly-L-arginine was attenuated by ouabain, but was unaffected by glybenclamide. L-NOARG and oxyhemoglobin caused attenuation, but did not abolish this relaxation. Also, the relaxations was unaffected by methylene blue, verapamil, or the presence of a calcium-free bathing medium. The endothelium-dependent to poly-L-arginine relaxation was abolished only in vessels contracted with potassium chloride (40 mM) in the presence of L-NOARG and indomethacin.

Conclusion - These experiments indicate that poly-Larginine induces relaxation independent of nitric oxide.

Keywords: poly-L-arginine, polycations, nitric oxide, EDHF, endothelium

\footnotetext{
Section of Cardiovascular Surgery, Mayo Clinic, Rochester, Minnesota and Laboratório de Função Endotelial da Divisão de Cirurgia Experimental da Faculdade de Medicina de Ribeirão Preto - USP, São Paulo, SP

Mailing address: Paulo Roberto B. Evora - Rua Rui Barbosa, 367/15 - 14015-120 - Ribeirão Preto, SP, Brazil - E-mail: prbevora@keynet.com.br. Supported in part by: Mayo Foundation and FAPESP - Fundação de Amparo à Pesquisa e Ensino do Estado de São Paulo
}

Endothelium-derived relaxing factor(EDRF) and endothelium-derived hyperpolarizing factor (EDHF) induce vasodilation by unique mechanisms ${ }^{1}$. The active component of EDRF is the nitric oxide radical $(\mathrm{NO})^{2,3}$ that induces guanylate cyclase-mediated relaxation of vascular smooth muscle. The endothelial cell precursor of nitric oxide synthesis is L-arginine ${ }^{4}$, and nitric oxide-mediated vasodilation can be inhibited by Ng-monomethyl-L-arginine (L-NMMA) ${ }^{4}$ and $\mathrm{N}^{\mathrm{G}}$-nitro-L-arginine (L-NOARG) ${ }^{5}$ through competitive inhibition of endothelial cell metabolism of $\mathrm{L}$-arginine. However, exogenous L-arginine does not cause endothelium-dependent relaxation, although large molecular weight arginine-containing peptides do ${ }^{6,7}$. It has previously been reported that poly-L-arginine induces endothelium-dependent relaxation of the bovine pulmonary artery in a manner consistent with the stimulated release of endotheliumderived nitric oxide?

Activated leukocytes and platelets release polycations or cationic proteins into the vasculature that have been implicated in vascular disorders, such as vasodilatation, vasoconstriction, and increased vascular permeability ${ }^{8,9}$, as well as respiratory airway disorders ${ }^{10,11}$. Moreover, the content of $a$ and dense granules released by activated platelets, mainly platelet factor 4 and platelet-derived growth factor, which also have electrostatic properties, might play a role in the atherosclerotic process ${ }^{12}$. However, the precise mechanism(s) by which polycations bring about such vascular disorders is unknown, but it seems to be related to their electrostatic properties ${ }^{13-15}$. It has been previously reported that polycations stimulate arachidonic acid metabolism ${ }^{14,16}$ and that poly-L-arginine, a synthetic polycation, induces endothelium-dependent relaxation in bovine pulmonary arteries ${ }^{7}$ and canine cerebral arteries ${ }^{13}$ in a manner consistent with the stimulated release of nitric oxide. Evora et a ${ }^{17}$ found that poly-Larginine also elicits endothelium dependent relaxation in normal and reperfused canine coronary arteries, but the mechanism was not investigated. These data motivated this laboratory investigation on the mechanisms of canine coronary 
artery relaxation induced by poly-L-arginine. To increase knowledge about the pharmacological properties of poly-Larginine, and other polyamine rich in arginine, it is fundamental to test them as possible "pharmacological tools" to study the endothelium-dependent vascular reactivity.

\section{Methods}

Heartworm-free mongrel dogs (25-30 kg) of either sex were anesthetized with pentobarbital sodium $(30 \mathrm{mg} / \mathrm{kg}$ intravenous injection; Fort Dodge Laboratories, Inc., Fort Dodge, Iowa) and exsanguinated via the carotid arteries. The chest was quickly opened, and the beating heart was harvested and immersed in cool, oxygenated physiological salt solution of the following composition (mM): $\mathrm{NaCl} 118.3$, $\mathrm{KCl} 4.7, \mathrm{MgSO}_{4} 1.2, \mathrm{KH}_{2} \mathrm{PO}_{4} 1.22, \mathrm{CaCl}_{2} 2.5, \mathrm{NaHCO}_{3} 25.0$, and glucose 11.1 (control solution). The procedures and handling of the animals were reviewed and approved by the Institutional Animal Care and Use Committee of the Mayo Foundation.

The left circumflex coronary artery was carefully dissected free and segments (4-5 mm in length) of blood vessel were prepared for in vitro experiments. Great care was taken not to touch the intimal surface of the vascular segments. In some of the segments in which vascular smooth muscle function was to be tested without the influence of the endothelium, the endothelium was removed by gently rubbing the intimal surface of the blood vessel with a pair of watchmakers' forceps. Vascular segments with and without endothelium were suspended in organ chambers $(25 \mathrm{~mL})$ filled with control solution maintained at $37^{\circ} \mathrm{C}$ and bubbled with $95 \% \mathrm{O}_{2} / 5 \% \mathrm{CO}_{2}(\mathrm{pH}=7.4)$. Two stainless steel clips passed through its lumen suspended in each ring. One clip was anchored to the bottom of the organ chamber, and the other was connected to a strain gauge for measurement of isometric force (Statham UC 2, Gould, Cleveland, Ohio). The rings were placed at the optimal point of their length-tension relation by progressively stretching them until contraction to potassium ions $(20 \mathrm{mM})$, at each level of distension, was maximal. In all experiments, the presence or absence of endothelium was confirmed by determining the response to acetylcholine $\left(10^{-6} \mathrm{M}\right)$ in rings contracted with potassium ions $(20 \mathrm{mM})$. After optimal tension was achieved, the coronary artery rings were allowed to equilibrate in control solution for 30-45 minutes before administration of drugs. In all experiments, indomethacin $\left(10^{-6} \mathrm{M}\right)$ was used to prevent synthesis of endogenous prostanoids. Endothelium-derived relaxing factor and endothelium-derived hyperpolarizing factor are not prostanoids, and blockers of cyclooxygenase do not attenuate endothelium-dependent relaxation by these mechanisms.

Control dose-response curves to poly-L-arginine $\left(10^{-11}\right.$ to $\left.10^{-7} \mathrm{M}\right)$ in vessels contracted with prostaglandin $\mathrm{F}_{2 \alpha}(2,5 \mathrm{X}$ $\left.10^{-6} \mathrm{M}\right)$ were obtained in the presence of indomethacin $\left(10^{-6}\right.$ $\mathrm{M})$. Also, these dose-response curves were performed in vessels incubated with $\mathrm{N}^{\mathrm{G}}$-nitro-L-arginine $\left(10^{-5} \mathrm{M}\right), \mathrm{Ng}$-monomethyl-L-arginine $\left(10^{-5} \mathrm{M}\right)$, oxyhemoglobin $\left(10^{-5} \mathrm{M}\right)$, ou- abain $\left(10^{-5} \mathrm{M}\right)$, glibenclamide $\left(10^{-5} \mathrm{M}\right),( \pm)$ verapamil hydrochloride $\left(10^{-6} \mathrm{M}\right)$, and methylene blue $\left(10^{-5} \mathrm{M}\right)$.

Dose-responses curves to poly-L-arginine $\left(10^{-11}\right.$ to $10^{-7}$ M) were obtained in vessels immersed in calcium-free Krebs solution and in vessels contracted with $20 \mathrm{mM}$ and $40 \mathrm{mM}$ of potassium chloride to study hyperpolarization. Also, in vessels contracted with potassium, experiments were performed in the presence of indomethacin $\left(10^{-6} \mathrm{M}\right)$ in vessels and the $\mathrm{N}^{\mathrm{G}}$-nitro-L-arginine higher concentration $\left(2 \times 10^{-4} \mathrm{M}\right)$.

The following drugs were used: acetylcholine chloride, EGTA, glibenclamide, indomethacin, ouabain, poly-L-arginine hydrochloride (M.W. $=139,200$ ), prostaglandin $\mathrm{F}_{2 \alpha}$, methylene blue, $\mathrm{N}^{\mathrm{G}}$-nitro-L-arginine, and $( \pm$ ) verapamil hydrochloride (all from Sigma Chemical Company, St. Louis, Missouri). D-arginine, L-arginine, and Ng-monomethyl-L-arginine were obtained from Calbiochem, San Diego, California. All drugs were prepared with distilled water except for indomethacin, which was dissolved in $\mathrm{Na}_{2} \mathrm{CO}^{3}\left(10^{-5} \mathrm{M}\right)$. Oxyhemoglobin was prepared utilizing according to the method of Gillespie and Sheng ${ }^{18}$. The drug concentrations are expressed as final molar concentrations in the organ chambers. When Ng-monomethyl-L-arginine, $\mathrm{N}^{\mathrm{G}}$-nitro-L-arginine, hemoglobin, or ouabain were used, vascular segments were incubated with the compounds at least 15 minutes prior to contraction with prostaglandin $\mathrm{F}_{2 \alpha}$. When glibenclamide, verapamil, methylene blue, or calcium-free solutions were used, vascular segments were incubated for at least $40 \mathrm{mi}-$ nutes prior to contraction. Calcium-free solution was prepared by exchanging the calcium in the control solution with potassium chloride with the addition of calcium-EGTA $(0.016 \mathrm{mM})$.

Results are expressed as means \pm SEM. In all experiments, $\mathrm{n}$ refers to the number of animals from which blood vessels were taken. In segments contracted with prostaglandin $\mathrm{F}_{2 \alpha}$, responses are expressed as percentage changes from the contracted levels. Statistical evaluation of data was performed with the Student $t$ test for either paired or unpaired observations. Values were considered to be statistically significant when $P$ was less than 0.05 .

\section{Results}

Poly-L-arginine $\left(10^{-11}\right.$ to $\left.10^{-6} \mathrm{M}\right)$ induced concentration-dependent relaxation of contracted coronary artery segments with endothelium, which completely counteracted the direct constrictive effect of prostaglandin $\mathrm{F}_{2 \alpha}$ on the vascular smooth muscle $(n=10)$. Poly-L-arginine caused a modest decrease in tension in coronary artery segments without endothelium (figs. 1 and 2). The additional nitric oxide synthase blocking caused endothelium-dependent relaxation impairment, but with significant differences between vessels with and without endothelium (figs. 3 and 4).

Pretreatment with ouabain $\left(10^{-5} \mathrm{M}\right)$ inhibited the endothelium-dependent relaxation to poly-L-arginine but did not alter the modest relaxation effect on the vascular smooth muscle. Glibenclamide $\left(10^{-6} \mathrm{M}\right)$ did not impair relaxation to poly-L-arginine (fig. 5). 


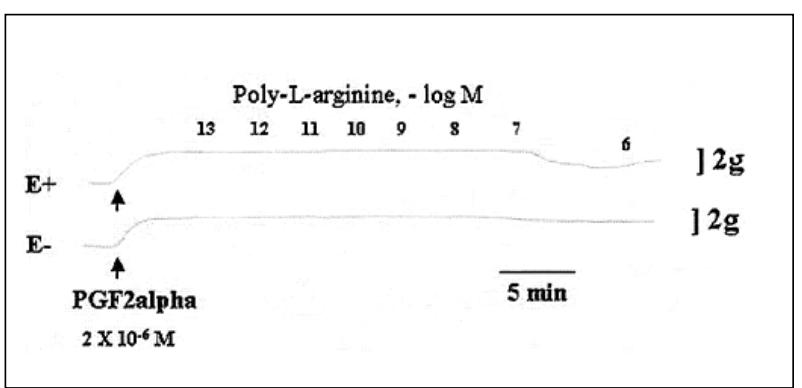

Fig. 1 - Endothelium-dependent relaxation to poly-L-arginine. Original doseresponse curve.

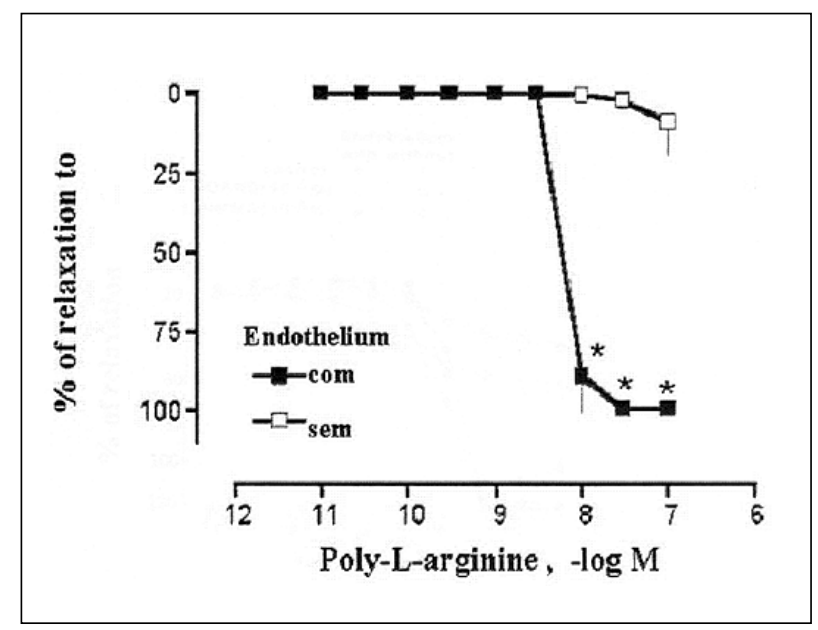

Fig. 2 - Endothelium-dependent relaxation to poly-L-arginine. Canine coronary artery segments, with and without endothelium, were contracted with prostaglandin $\mathrm{F}_{2 \alpha}$. Following stabilization of contraction, segments were exposed to increasing concentrations of poly-L-arginine (M.W.=139,200). Experiments were performed in the presence of indomethacin $\left(10^{-6} \mathrm{M}\right)$. Values are presented as means \pm SEM. Differences were considered significant when $\mathrm{P}<0.05$.

When the coronary rings were contracted with potassium chloride $(20 \mathrm{mM})$, the dose response-curves to poly-L-arginine were shifted to the right, and the relaxations were significantly different from those curves obtained in prostaglandin $\mathrm{F} 2 \propto$ contracted vessels $\left(\mathrm{P}<0.05\right.$ for $10^{-8} \mathrm{M}$ and $\mathrm{P}<0.001$ for $3 \times 10^{-8}$ to $10^{-7} \mathrm{M}$ ). When the coronary rings were contracted with $40 \mathrm{mM}$ of potassium chloride the endothelium-dependent relaxations to poly-L-arginine were completely eliminated (fig. 6).

Incubation in calcium-free solution and in the presence of verapamil $\left(10^{-6} \mathrm{M}\right)$ methylene blue $\left(10^{-6} \mathrm{M}\right)$ did not modify endothelium-dependent relaxation to poly-L-arginine (fig. 7).

\section{Discussion}

The present study demonstrates that in the canine coronary artery, endothelium-dependent relaxation evoked by poly-L-arginine is not mediated by endothelium-derived nitric oxide. Indeed, L-NMMA and L-NOARG, competitive inhibitors of endothelial cell synthesis of nitric oxide from L$\operatorname{arginine}^{4,5}$, failed to attenuate endothelium-dependent relaxation to poly-L-arginine. These compounds do inhibit endothelium-dependent relaxation evoked by other

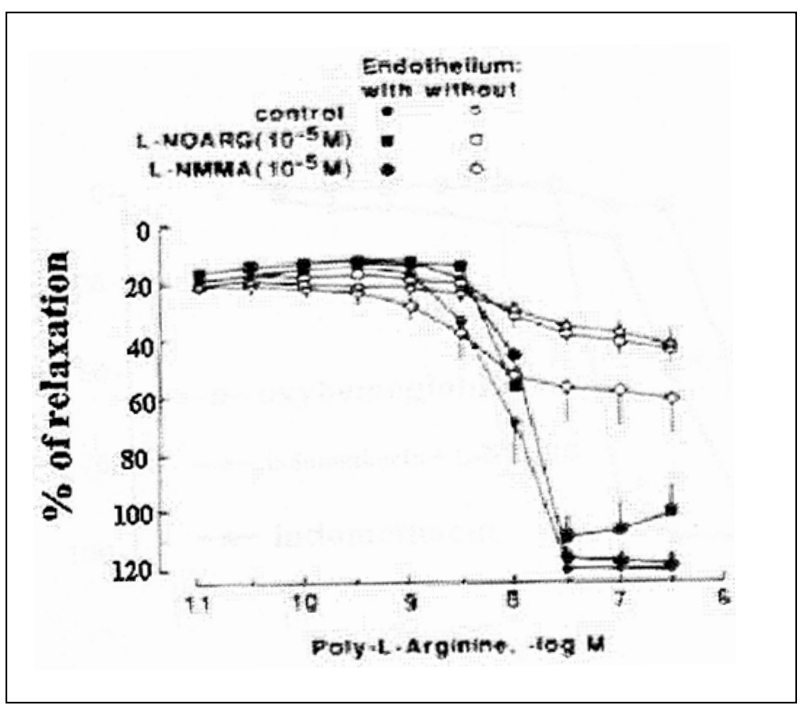

Fig. 3 - Endothelium-dependent relaxation to poly-L-arginine. Canine coronary artery segments, with and without endothelium, were contracted with prostaglandin $\mathrm{F}_{2 \alpha}$. Following stabilization of contraction, segments were exposed to increasing concentrations of poly-L-arginine (M.W. $=139,200$ ). Experiments were performed in the presence of indomethacin $\left(10^{-6} \mathrm{M}\right)$. When Ng-monomethyl-L-arginine (L-NMMA; $10^{-}$ ${ }^{5} \mathrm{M}$ ) or $\mathrm{N}^{\mathrm{G}}$-nitro-L-arginine (L-NOARG; $10^{-5} \mathrm{M}$ ) was used, the compounds were added to the organ bath at least 15 minutes prior to contraction with prostaglandin. Values are presented as means \pm SEM. Differences were considered significant when $\mathrm{P}<0.05$.

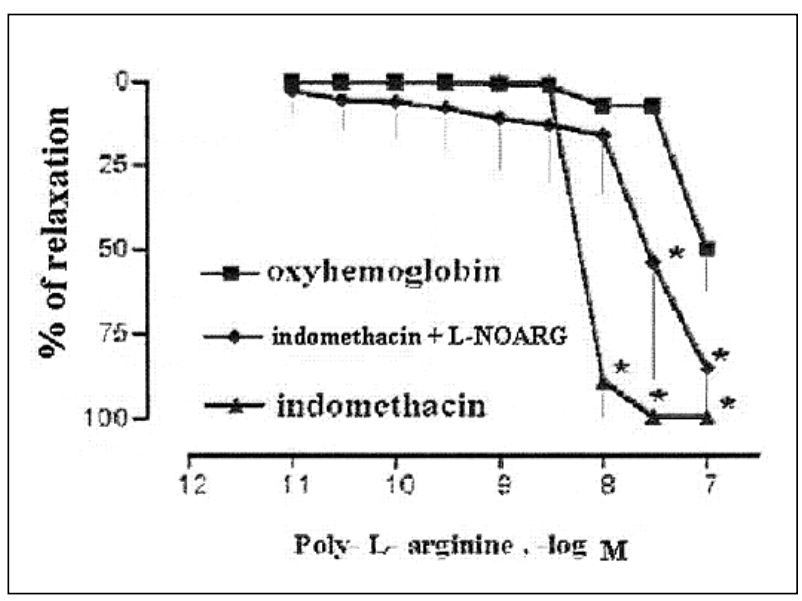

Fig. 4 - Endothelium-dependent relaxation to poly-L-arginine. Canine coronary artery segments, with and without endothelium, were contracted with prostaglandin $\mathrm{F}_{2 \alpha}$. Following stabilization of contraction, segments were exposed to increasing concentrations of poly-L-arginine (M.W. $=139,200)$. Experiments were performed in the presence of indomethacin $\left(10^{-6} \mathrm{M}\right)$, indomethacin plus $\mathrm{N}^{\mathrm{G}}$-nitro-L-arginine (LNOARG; $\left.10^{-5} \mathrm{M}\right)$, and oxyhemoglobin $\left(10^{-5} \mathrm{M}\right)$. The compounds were added to the organ bath at least 15 minutes prior to contraction with prostaglandin. Values are presented as means \pm SEM. Differences were considered significant when $\mathrm{P}<0.05$.

agonists, such as acetylcholine and adenosine diphosphate. In addition, methylene blue, which inhibits endothelium-dependent relaxation to nitric oxide by inactivating soluble guanylate cyclase in the vascular smooth muscle ${ }^{3}$, also failed to attenuate poly-L-arginine-mediated relaxation. Our findings differ from studies in the bovine pulmonary artery and vein where endothelium-dependent relaxation to poly-L-arginine was inhibited by methylene blue ${ }^{7}$. These conflicting data may be due to heterogeneity between species, blood vessels of varying anatomic locations, or both of these. 


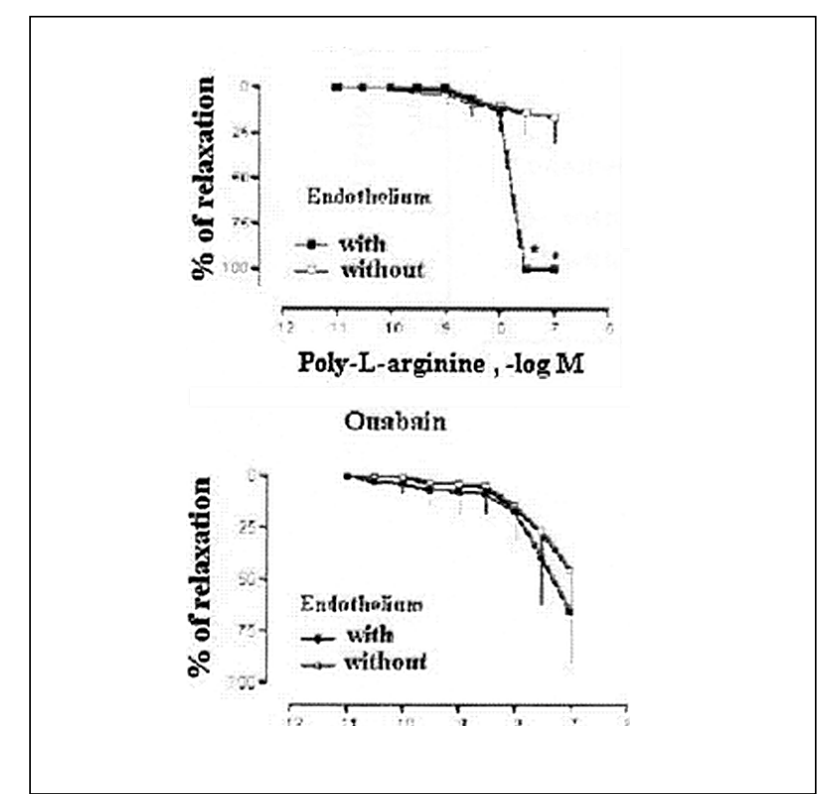

Fig. 5 - Endothelium-dependent relaxation to poly-L-arginine. Canine coronary artery segments, with and without endothelium, were contracted with prostaglandin $\mathrm{F}_{2 \alpha}$. Following stabilization of contraction, segments were exposed to increasing concentrations of poly-L-arginine (M.W.=139,200). Experiments were performed in the presence of indomethacin $\left(10^{-6} \mathrm{M}\right)$. Coronary vessels were incubated with glibenclamide $\left(10^{-6} \mathrm{M}\right)$ and ouabain $\left(10^{-5} \mathrm{M}\right)$. The compounds were added to the organ bath at least 15 minutes prior to contraction with prostaglandin. Values are presented as means \pm SEM. Differences were considered significant when $\mathrm{P}<0.05$

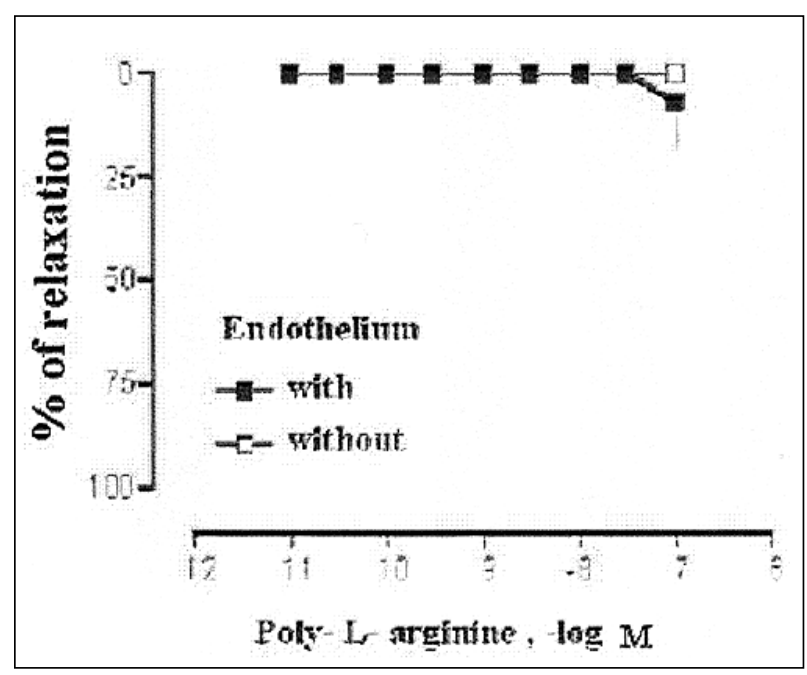

Fig. 6 - Endothelium-dependent relaxation to poly-L-arginine. Canine coronary artery segments, with and without endothelium, were contracted with potassium chloride $40 \mathrm{mM}$. Values are presented as means \pm SEM. Differences were considered significant when $\mathrm{P}<0.05$

Oxyhemoglobin, which inhibits nitric oxide-mediated endothelium-dependent relaxation by binding the radical ${ }^{18}$, attenuated endothelium-dependent relaxation to poly-Larginine. Although this finding might be interpreted as sup-

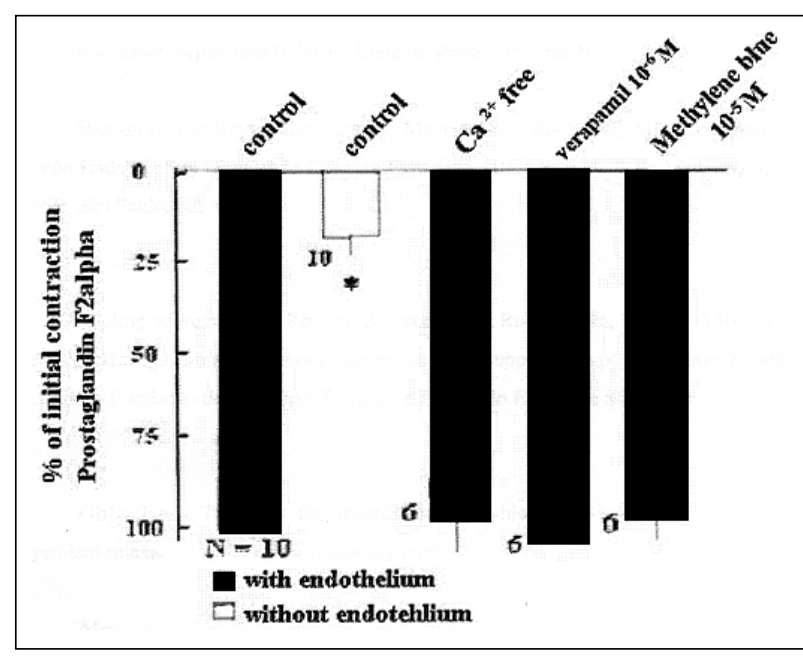

Fig. 7 - Endothelium-dependent relaxation to poly-L-arginine. Canine coronary artery segments, with and without endothelium, were contracted with prostaglandin $\mathrm{F}_{2 \alpha}$. Following stabilization of contraction, segments were exposed to $10^{-7} \mathrm{M}$ poly$\mathrm{L}$-arginine $(\mathrm{M} . \mathrm{W} .=139,200)$. Experiments were performed in the presence of indomethacin $\left(10^{-6} \mathrm{M}\right)$. When verapamil $\left(10^{-6} \mathrm{M}\right)$, calcium-free solution, or methylene blue $\left(10^{-5} \mathrm{M}\right)$ were used, the compounds were added to the organ bath at least 40 minutes prior to contraction with prostaglandin $\mathrm{F}_{2 \alpha}$. Values are presented as means \pm SEM. Asterisk denotes significance from control endothelium-dependent relaxation to polyL- arginine $(\mathrm{P}<0.05)$.

port for the hypothesis that part of the relaxation to the polypeptide is due to nitric oxide, it must be remembered that hemoglobin has a very high affinity for anionic compounds like poly-L-arginine. Thus, the hemoglobin-polyL-arginine interaction is most likely charge-specific and thus may interfere with receptor binding. These results indicate that hemoglobin is not a good tool to study endotheliumdependent relaxation to anionic compounds.

The mechanism by which poly-L-arginine induces vascular relaxation is an enigma. The results of this investigation in arteries contracted with potassium chloride and in the presence of glibenclamide and ouabain permit speculation that poly-L-arginine stimulates the release of an endothelium-dependent factor different from nitric oxide, prostacyclin, or both of these. It is tempting to speculate that the endothelium releases a hyperpolarizing factor that mediates relaxation ${ }^{19}$. Hoeffner and coworkers have used ouabain as a tool to distinguish between 2 distinct relaxing factors produced by the endothelium of the canine coronary artery ${ }^{20}$. There fore, it is possible that in the canine coronary artery, poly-L-arginine is a specific stimulator of the release of a non-nitric oxide, endothelium-derived relaxing factor. Thus, the compound could be an important tool for investigating the physiology of non-nitric oxide endothelium-dependent relaxation However, additional investigations using specific potassium channels blockers will be important to elucidate the actions of a possible endothelium-dependent hyperpolarizing factor in the poly-L-arginine induced relaxations ${ }^{21-23}$. 


\section{References}

1. Feletou M, Vanhoutte PM. Endothelium-dependent hyperpolarization of canine coronary smooth muscle. Br J Pharmacol 1988;93:515-24.

2. Palmer RMJ, Ferrige AG, Moncada, S. Nitric oxide accounts for the biological activity of endothelium-derived relaxing factor. Nature 1987;327:524-6.

3. Ignarro LJ, Buga GM, Wood KS, Byrns RE, Chaudhuri G. Endothelium-derived relaxing factor produced and released from artery and vein is nitric oxide. Proc Natl Acad Sci USA 1987;84:9265-9.

4. Rees DD, Palmer RMJ, Hodson HF, Moncada S. Aspecific inhibitor of nitric oxide formation from L-arginine attenuates endothelium-dependent relaxation. BrJPharmacol 1989;96:418-24.

5. Moore PK, al-Swayeh OA, Chong RA, Evans RA, Gibson A. L-N ${ }^{\mathrm{G}}$-nitro arginine (L-NOARG), a novel, L-arginine-reversible inhibitor of endothelium-dependent vasodilatation in vitro. Br J Pharmacol 1990;99:408-12.

6. Thomas G, Mostaghim R, Ramwell PW. Endothelium-dependent vascular relaxation by arginine containing polypeptides. Biochem Biophys Res Comm 1986;141:446-51.

7. Ignarro LJ, Gold ME, Buga GM, et al. Basic polyamino acids rich in arginine, lysine, or ornithine cause both enhancement of and refractoriness to formation of endothelium-derived nitric oxide in pulmonary artery and vein. Circ Res 1989; 64:315-29.

8. Thomas G, Hecker M, Ramwell PW. Vascular activity of polycations and basic amino acids: L-arginine does not specifically elicit endothelium-dependent relaxation. Biochem Biophys Res Commun 1989;158:177-80.

9. Westergren I, Johansson BB. Altering the blood-brain barrier in the rat by intracarotid infusion of polycations: a comparison between protamine, poly-L-lysine and poly-L- arginine. Acta Physiol Scand 1993;149:99-104

10. CoyleAJ, Uchida D, Ackerman SJ, Mitzner W, Irvin CG. Role of cationic proteins in the airway. Hyperresponsiveness due to airway inflammation. Am J Respir Crit Care Med 1994;150:S63-71.

11. Ginsburg I. Cationic polyelectrolytes: potent opsonic agents which activate the respiratory burst in leukocytes. Free Radic Res Commun 1989;8:11-26.
12. Hyslop S, de Nucci G. Heparin, polycations, and atherosclerosis. Semin Thromb Hemost 1993;19:89-98.

13. Kinoshita H, Katusic ZS. Nitric oxide and effects of cationic polypeptides in canine cerebral arteries. J Cereb Blood Flow Metab 1997;17:470-80.

14. Needham L, Hellewell PG, Williams TJ, Gordon JL. Endothelial functional responses and increased vascular permeability induced by polycations. Lab Invest 1988;59:538-48.

15. Vepa S, Scribner WM, Natarajan V. Activation of endothelial cell phospholipase D by polycations. Am J Physiol 1997;272: L608-13.

16. Alavi N. Effect of polycations on prostaglandin synthesis in cultured glomerular mesangial cells. Biochim Biophys Acta 1990;1042:221-6.

17. Evora, PR, Pearson PJ, SchaffHV. Impaired endothelium-dependent relaxation after coronary reperfusion injury: evidence for G-protein dysfunction. Ann Thorac Surg 1994;57:1550-6.

18. Gillespie JS, Sheng H. Influence of haemoglobin and erythrocytes on the effects of EDRF, a smooth muscle inhibitory factor, and nitric oxide on vascular smooth muscle. Br J Pharmacol 1988;95:1151-6.

19. Chen G, Hashitani H, Suzuki H. Endothelium-dependent relaxation and hyperpolarization of canine coronary artery smooth muscle in relation to the electrogenic Na-K pump. Br J Pharmacol 1989;98: 950-6.

20. Hoeffner U, Feletou M, Flavahan NA, Vanhoutte PM. Canine arteries release two different endothelium-derived relaxing factors. Am J Physiol 1989;257: H330-3.

21. Ge ZD, Zhang XH, Fung PC, He GW. Endothelium-dependent hyperpolarization and relaxation resistance to $\mathrm{N}(\mathrm{G})$-nitro-L-arginine and indomethacin in coronary circulation. Cardiovasc Res 2000;46:547-56.

22. Eckman D, Hopkins N, McBride C, Keef K. Endothelium-dependent relaxation and hyperpolarization in guinea-pig coronary artery: role of epoxyeicosatrienoic acid. Br J Pharmacol 1998;124:181-9.

23. Waldron GJ, Cole WC.Activation of vascular smooth muscle $\mathrm{K}+$ channels by endothelium-derived relaxing factors. Clin Exp Pharmacol Physiol 1999;26: 180-4. 